\title{
Discurso de recepción del Premio Nacional de Humanidades y Ciencias Sociales 2007
}

\author{
Manuel Antonio Garretón*
}

Gracias al Estado de Chile por este Premio, gracias a mis maestros en la sociología, a mis colegas, a mis estudiantes y ayudantes, a mis padres (hoy fallecidos), a mis hermanos y mis hijos, a mis amigos y amigas, a quienes he amado y me han amado, a todos los que han hecho de mí alguien que, en algún momento de su vida, pudiera merecer este Premio.

He dicho a lo largo de estos meses que este es un Premio no sólo a una persona, sino a una generación o, mejor, a varias generaciones que han destinado sus vidas a cultivar una disciplina o, también mejor, varias disciplinas, porque la sociología, la ciencia política, la antropología, la psicología y psicología social, las Ilamadas ciencias sociales, pese a su diversidad de saberes y oficios, son parte de una misma búsqueda y un mismo quehacer. Es a esta actividad que compromete la vida de muchos, que se le ha dado el Premio de Ciencias Sociales y Humanidades por primera vez, porque antes, y con todos los merecimientos del caso, se había reconocido otros campos y dimensiones como la filosofía, las ciencias jurídicas, la economía. No deja de ser importante que este año, justo cuando se cumplen cincuenta años de la instalación de la carrera de sociología en Chile, se otorgue este Premio por primera vez a un sociólogo de profesión, pero que es también politólogo y comparte la misma vocación que las otras ciencias sociales mencionadas.

Es al finalizar la década del cincuenta que nace la sociología en Chile y posteriormente, con mucho más retardo, la ciencia política moderna. Lo hace marcada por la gran esperanza que, ante la problemática del desarrollo y las Ilamadas reformas estructurales que permean toda la sociedad y los actores que en ella se mueven, podrá dar producir conocimientos y profesionales que puedan enfrentar dicha problemática que la dimensión económica es incapaz de agotar. Las ciencias sociales, predominantemente la sociología, nacen como ciencias sociales del desarrollo. Poco a poco, se desprenderán de las teorías que vienen de otros contextos y buscarán generar nuevos conceptos para entender lo que ocurría en nuestras sociedades asumiendo la idea de la revolución como el eje que reemplaza la problemática del desarrollo. Había aquí una dimensión científica y

* Doctor en Sociología de la Escuela de Altos Estudios en Ciencias Sociales, París, y docente del Departamento de Sociología de la Universidad de Chile. 
profesional, pero también una ética e intelectual que buscaba no sólo comprender sino también transformar la sociedad, el país en que vivíamos. En este esfuerzo, la sociología, buscando transformaciones y utopías que le dieran un sentido metacientífico a su actividad, se confundirá muchas veces con los actores sociales y políticos, perdiendo su autonomía y distancia respecto de los proyectos ideológicos. Esta autonomía y distancia, el desgarro entre reflexión y acción, son indispensables si se quiere efectivamente contribuir al proyecto que cada uno persigue. La falta de distancia, lo que algunos han Ilamado el ideologismo de los sesenta y setenta, por comprensible que fuera, afectaba y perjudicaba los propios proyectos con que los sociólogos e intelectuales se identificaban. A mi juicio, quedamos en deuda con una sociedad que necesitaba desesperadamente de esa distancia, lo que no significaba en ningún caso "pasar por el campo de batalla con una flor en la mano", sino ser capaces en el mismo compromiso de mostrar los límites de los proyectos en juego, más que ser sus apologetas. Creo muy sinceramente que esa deuda ha sido pagada con creces por nuestra y las siguientes generaciones que rescataron las ciencias sociales del proceso destructivo que sobrevendría más adelante.

Porque luego vino el horror y la represión (no nos olvidemos de la frase de un general de la Junta Militar señalando que con los sociólogos no serían duros sino crueles, y lo fueron... pero no sólo con los sociólogos): la profesión de cientista social se transformó en prontuario y los estudiantes que hasta hacía poco eran miembros de la élite dirigente del país pasaron a ser parias. Y nuestra tarea como generación fue juntar los pedazos de lo que sabíamos hacer, crear instituciones fuera de las universidades y parafraseando a Barrault respecto del teatro en la Francia del 68, aceptar que ahí donde había una gente que quisiera entender y unos mínimos conceptos, ideas o instrumentos para hacerlo con rigor, habría sociología y ciencias sociales. Y todos sabemos lo que estas disciplinas hicieron para estudiar cada proceso, cada actor, cada situación de la dictadura, para formar nuevas generaciones, para llegar a los distintos lugares del país sin mayores recursos, para proyectarse en las publicaciones que los sectores democráticos habían construido, para construir instituciones, y también y sobre todo para descubrir en los análisis del pasado y presente las raíces de la crisis y la derrota y las posibles salidas. Desde estas disciplinas, en diálogo crítico y solidario con la política y los actores sociales, surgió la temática y el ideal de la democracia, el estudio de las transiciones y sus posibilidades para Chile, la perspectiva de unidad de los sectores democráticos. El aporte teórico y técnico de las ciencias sociales para enfrentar el Plebiscito de 1988 fue insustituible.

Hace diecisiete años que Chile vive en democracia política, sin duda incompleta y presa de la institucionalidad heredada como lo prueba la ausencia de una Constitución surgida de un momento constitucional del pueblo, finalmente el único soberano. Nadie podría negar las profundas transformaciones estructurales y sociales y el crecimiento económico vivido por nuestro país.

En este contexto, ¿qué desafíos enfrentan las ciencias sociales y cuál puede ser su aporte?

Siempre he dicho que la sociología y toda ciencia social son a la vez la ciencia de la sospecha y la ciencia de la compasión. Hoy día eso tiene enorme vigencia. Sospecha de 
una sociedad que parece lanzada en el desarrollo y la globalización, pero carente de una identidad y cultura que le dé un sentido colectivo. Sospecha de consensos que ocultan la falta y el temor al debate y la confrontación y que por lo tanto implican no consenso sino acomodación a situaciones de poder y muchas veces chantajes de los poderosos. Sospecha que la modernidad copiada y la felicidad alcanzada en el consumo y las expectativas individuales oculta la falta de un proyecto nacional que le dé sentido y perspectiva de futuro. Sospecha que las propuestas para este futuro muy bien intencionadas no van al fondo de la profunda transformación y redistribución de la riqueza y el poder que debe sufrir nuestra convivencia para ser efectivamente una comunidad ética, política y socioeconómica, campo en el cual las desigualdades amenazan con destruir toda idea de país como empresa colectiva nacional. Pero todo ello no es el producto de un puro afán crítico sino que va acompañado de la compasión en el profundo sentido de "padecer con". Y la compasión significa básicamente hacer de nuestras disciplinas y de nuestro trabajo, más allá de la sospecha, un instrumento de emancipación de cualquier tipo de dominación u opresión. Es decir, la combinación intrínseca a nuestra vocación del principio ético-científico de la verdad y del principio éticopolítico de la justicia. Nos debemos a ambos en forma irrenunciable.

Las ciencias sociales, las ciencias más generalmente, nacieron contra el oscurantismo que imponían en otra época las religiones. En nuestros países también han debido luchar contra otros oscurantismos. Si el ideologismo significó un cierto oscurantismo que no superamos sino tardíamente, si el autoritarismo de la dictadura fue sin duda el momento más oscurantista de nuestra historia en que las nuevas religiones fueron la seguridad nacional y la doctrina económica de los Chicago, hoy día enfrentamos nuevos oscurantismos contra los cuales las ciencias sociales y la sociología deben luchar para ser fieles a su vocación y para efectivamente ser un aporte al país. Ellos provienen, sobre todo, de los medios de comunicación y los poderes fácticos, que inventan un clima de opinión pública que impide conocernos lo que somos y lo que podemos ser. Y para ello utilizan los mismos instrumentos de las ciencias sociales, como las encuestas, los grupos de discusión, en manos de especialistas de mercado pero ignorantes de lo social y psicológico, para inventar y manipular una imagen de sociedad, que luego nos proyectan a través de esos mismos medios. El espacio que en otra época ocuparon las ciencias sociales hoy lo ocupan gurúes mediocres o especialistas de imagen y mercado, opinólogos, o simplemente mercenarios del pensamiento.

Es cierto que ha habido un renacimiento y florecimiento de las disciplinas de las ciencias sociales, una veintena de carreras de sociología, muchas más de psicología, una decena de ciencia política, mayores fondos para proyectos aunque muy tardíamente. Y hace poco la Presidenta anunciaba en la Universidad de Chile un plan de recuperación y fortalecimiento de las ciencias sociales y humanidades. Hay que felicitarse por esto, al mismo tiempo que quisiera señalar tres preocupaciones al respecto.

En primer lugar, con la excepción de la psicología ninguna otra profesión o disciplina de las ciencias sociales tiene el carácter de exclusivamente universitaria: la aberrante ley que data de la dictadura y que reconocía sólo doce carreras propiamente universitarias ha sido sólo parcialmente modificada y en esas modificaciones no se han incluido la sociología, la antropología, la ciencia política, por nombrar algunas. 
En segundo lugar, no se ha hecho en serio y sin apresuramientos o descalificaciones un debate sobre la política nacional-estatal respecto del desarrollo científico-social. Lo que hay, por un lado, es una tendencia del Estado a buscar otros campos del desarrollo científico fuera de las universidades, experiencias que en otros países han sido muy exitosas a condición que se trate de instituciones públicas y en diálogo con las universidades. Por otro lado, en las universidades, carentes de los recursos que les corresponden, existe una reacción descalificadora frente a nuevas iniciativas institucionales. Tales iniciativas no pueden hacerse por imposición inconsulta del Estado frente a las universidades, pero estas últimas deben abrirse a discutir y proyectar nuevas formas institucionales de desarrollo sin negarles legitimidad. Es necesario un diálogo responsable y respetuoso sin el cual nuestro retraso científico cultural será inevitable. Ejemplos de ello son una política estatal-universitaria que favorezca el desarrollo de metodologías como las encuestas y que evite el abuso que se hace hoy de ellas, como ya lo indicamos, o el uso del conocimiento por parte de las políticas públicas.

En tercer lugar, mi preocupación va hacia la convergencia entre el aporte de las ciencias sociales y nuestro horizonte como país. Es cierto que la mayor expansión de las profesiones, las instituciones universitarias, los proyectos de investigación han significado una recuperación de las disciplinas y que ellas aportan hoy un caudal importante de conocimiento a las políticas públicas, el que podría ser mejorado si se hacen los cambios institucionales mencionados. Pero más allá de los indispensables conocimientos sectoriales y parciales, el país no parece haberse preguntado por una problemática central, como lo fueran el desarrollo, la integración de clases medias y sectores populares, las reformas estructurales, la democracia en otra época. Llegamos al bicentenario sin un proyecto de país, sin que nos planteemos la pregunta de lo que queremos ser como comunidad histórica más allá de los éxitos, aspiraciones o biografías personales o familiares. De nuevo, la mejor expresión de ello es que no tenemos una Constitución democrática, pero sobre todo que ello no parece importarnos. Nuestros debates son pobrísimos, como lo refleja la miseria de nuestros medios de comunicación, es más, descalificamos los debates y conflictos democráticos en aras del consenso aparente y los reducimos sólo a su dimensión de lucha por el poder, con lo que le quitamos a la política su base misma que es el debate y la lucha por proyectos alternativos, los espacios públicos apenas existen (además, carecemos de una verdadera televisión pública) y son copados por el consumo y la banalidad, sin duda con excepciones como lo acabamos de comprobar con Teatro a mil. La fragmentación y diversidad de las ciencias sociales enriquece la formación y también el conocimiento sectorial, pero no nos dan las respuestas de sentido que necesitamos urgentemente como país.

Si tuviéramos que definir una problemática histórica, ella es incluso mucho más compleja que las de otras épocas que hemos mencionado, y es la de refundarnos como nación multicultural, como comunidad ética en torno a los principios y valores de los derechos humanos, como comunidad socioeconómica que establece una distancia mínima y razonable entre sus diversas categorías, como comunidad política que genera su propia institucionalidad. Definir y aportar en esta refundación en sus diversas dimensiones, es nuestra tarea esencial. Pero para ello necesitamos espacios institucionales de producción de conocimientos e ideas, 
de debates y de encuentro con otros ámbitos de la sociedad, y medios de expresión de los que carecemos aunque gocemos de libertades.

Permítanme terminar con una nota personal. Evoco aquí tres reflexiones de ese gran padre, maestro, hermano y amigo que ha sido en mi vida Alain Touraine. La primera es la pregunta ¿por qué he corrido tanto? Y cuando trato de contestarla y veo mi vida pública dentro de mi generación, por un lado, creo haber sido el que más fuertemente ha sufrido el desgarro entre la necesidad de comprender, enseñar, analizar (y un cantautor diría que para comprender, distinguir y analizar "me hacen falta tus ojos claros") y el impulso de participar, ser protagonista, intervenir. La respuesta a esta pregunta la encuentro en una segunda fórmula del mismo Touraine: solitario, pero siempre solidario, porque lo que he, hemos, querido hacer es buscar signos de reunión donde se cruzan los caminos como diría Neruda y, como quería él de sus poemas, buscar que mis trabajos fueran como instrumentos útiles, como panes para el hambre de conocer y entender de la gente. Es cierto, confundí muchas veces la denuncia, la interpretación con la descalificación, por ello pido perdón. Pero hoy día siento que este Premio le da un sentido a lo que he hecho más allá de mi mismo y las vanidades personales. Al mismo tiempo es un llamado a asumir que hay una responsabilidad para adelante que no se agota en el reconocimiento de lo pasado. La tercera evocación de Touraine es el título de uno de sus libros "Un deseo de historia". Esa ha sido mi aspiración, formar parte de la historia desde un ángulo determinado. Y la duda permanente sobre si uno ha tenido la dignidad para esa tarea. Quizás el Premio sea una respuesta afirmativa a esa duda. Y si lo es, es porque a algunos y algunas lo que hemos hecho, personal y generacionalmente, les ha servido como punto de encuentro y reflexión, como pan para su hambre de comprensión, como una manera, y esa es la vocación de la sociología y la ciencia social, de juntar la biografía personal con su propio deseo de historia. Y, por lo tanto, el Premio es para todos ellos, está destinado a todos nosotros.

Muchas gracias 